\title{
Knowledge, Attitudes and Behavior of University Students towards Environmental Issues in Indonesia
}

\author{
Ma'rufa*, Sari Suryaa ${ }^{a}$ Putu Dessy Apriliany ${ }^{b}$ \\ ${ }^{a}$ Department of Management, Andalas University, Padang, West Sumatra, Indonesia \\ ${ }^{b}$ Department of Economics, Udayana University, Denpasar, Bali,Indonesia \\ *Corresponding author: marufridwan@gmail.com
}

\begin{abstract}
This paper presents an exploratory study examines environmental knowledge, attitude, behavior and the extent to which they are related among university students in Indonesia. Data collected from students of Andalas University at Sumatra Island, University of Indonesia at Java Island and University of Udayana at Bali Island. The results show that in the scale of 1 to 5 the mean score of environmental knowledge among three university students ranges from 4.380 to 4.460 . This range indicates that students have good knowledge about environmental issues. The mean score for environmental attitude ranges between 3.867 and 3.935. In scale of 1 to 5 this range indicate statement of fairly agree with six measurements of environmental attitude. In measurement of regulatory attitude, student's response ranges from 4.051 to 4.080 which indicate agreement towards stronger enforcement of environmental regulations. While for environmental behavior, students response show range from 3.589 to 3.683 which indicate that they quite interested in five potential actions they can involve in environmental protection. Based on compare mean analysis for all four variables, it was found that there is significant difference among three universities in environmental knowledge, environmental attitude, regulatory attitude and environmental behavior. The results of partial least square model confirmed that environmental knowledge affect environmental attitude, and then attitude affects environmental behavior intention. However, $\mathrm{R}$ square of environmental behavior only 0.323 which means there more than two third of decision on behaving environmentally is influenced by other factors.
\end{abstract}

Keywords: Environmental knowledge; attitude; behavior; university students; Indonesia

(c) 2016 Penerbit UTM Press. All rights reserved

\subsection{INTRODUCTION}

The implementation of Technical and Vocational Education implies change to many group of professionals including teachers, administrators, curriculum planners and other individual's charged with implementing educational policy [1]. The Nigeria's National Policy on Education was designed to train individuals to acquire knowledge and skills for self-reliant and national development. The policy further states that: "the trainees of Technical and Vocational program shall have three options: (1) secure employment either at the end of one or two modules of the whole course or after completing one or two modules of employable skills; (2) set-up their own business and become self- employed and be able to employ others; and (3) pursue further education in advance craft/technical program and in post secondary (tertiary) technical institutions such as science and technical colleges, polytechnics or colleges of education (technical) and universities" [2].

Environmental quality continues to decline in recent years both globally and nationally. Earth is experiencing severe pressure due to the exploitation of natural resources, air pollution and the difficulty of access to water resources. Handling of environmental issues became more urgent because of its important role in sustaining human life. If we look this situation more carefully, one of the sources of these problems may come from poor awareness of all stakeholders including government, businesses, consumers and community.

Education should be one of the key factors to develop awareness on the importance of environmental protection. Educational institutions have a very important role in spreading understanding about climate change and environmental protection, especially to the younger generations who will the future inhabitants of the earth. They should be equipped with adequate knowledge so that they can play an active role in addressing the climate change and environmental protection issues. Educational institutions will be in the forefront of creating a young generation who protect and preserve the environment. Education should bring immediate impact on elevation of knowledge and awareness that human being should involve in creating sustainable environment. Knowledge and awareness on the importance of environment sustainability should lead to positive attitude that maintaining environmental sustainability will reduce negative environmental impacts. In the end, accumulation of good knowledge and positive attitudes should lead to potential behaviors to perform an active role in protecting the environment.

According to the United Nations Conference on Environment and Development (UNCED), better known as the Earth Summit, environmental education is a process to build the world's population who are aware and concerned about the environment and all the problems associated with it, and people who have the knowledge, skills, attitudes and behavior, motivation and commitment to work together, both individually and collectively, in order to solve the current problems, and prevent the emergence of new environmental 
problems [1]. In Indonesia national education system, population and environmental issues has been taught and included in the basic and middle education educational curriculum in 1984. Later in 1986, the Ministry of Education and Culture put in the subject Population and Environment Education (PKLH). On May 21, 1996 the Ministry of Education and Culture and the Ministry of Environment issued a Joint Memorandum on Development and the Development of Environmental Education. Resumed on July 5, 2005, Minister of Environment and Minister of National Education issued a joint decree for the formation and development of environmental education, which should be done in integration with existing subject.

As per 2013, Indonesia has 59 state and 406 private universities [2]. These universities are spread all over the islands where the majority of population located in Java and Sumatra Islands. University is a higher educational institution that prepares graduates for immediate job market either in the public or private sectors and being self employed. These graduates will be actors and the decisionmakers in various fields including matters relating to environmental protection. If these graduates were not given sufficient education that emphasizes the importance of the awareness of environmental protection, it is difficult to expect what they decide will defend environmental sustainability.

As environment sustainability has been endorsed both internationally and nationally as an important issue, a university is supposed to have delivered appropriate level environmental education. To what extend this role has been implemented should be reflected by the level of current knowledge, attitude and environmental behavior of students. However, there is little exploration about profile of current knowledge, attitude and behavior of university students in Indonesia. Thus, this study investigated environmental knowledge, attitude and environmental behavior of students from three universities and analyzed any difference among three universities in Indonesia?

Investigation in this theme is needed because the current students are the beneficiaries of the latest developments as well as victims of environmental degradation. Dialectical identity is expected to make them more sensitive to environmental issues. Thus this study aims to obtain a baseline on the level of students' environmental knowledge, attitude and behavior. To measure is there any difference among three universities in three different locations. To investigate the extent to which knowledge, attitude and behavior are related.

Based on the context of this study, the facts show that Indonesia is a country with cultural diversity, vast territory and the different pressures faced by each region in environmental issues. It is conjectured that differences and diversity will impact on the awareness and consciousness about the environment. Thus, it is necessary to investigate whether there are differences of knowledge, attitudes and behavior among students which live in different locations. Investigation in three universities is a mean to gain multiple sources of evidences to support the data validity and the result that is considered as robust. To uncover it out, this study examined three groups of students in three different universities, namely Andalas University in West Sumatra, University of Indonesia in West Java and Udayana University in Bali.

\subsection{THEORETICAL FOUNDATION OF THE STUDY}

Environmental knowledge has been examined as a predictor that influences environmental behaviour. Higher scores on knowledge about environment was associated with increased engagement in environmental behaviours [3]. According to the theory of planned behaviour, environmental knowledge is assumed to be an antecedent of attitudes. Moreover, environmental knowledge is a common target of interventions under the assumption that increased knowledge will produce more environmentally responsible behavior [4]. The relationship of environmental knowledge to implicit environmental attitudes, however, is unknown, and the pathway from knowledge to behaviour in relation to intentions amongst university student in Indonesian context is not well understood.

Studies on environmental attitudes reveal that people generally claim favourable views about the environment [5]. These attitudes were reported to be only modestly related to environmental behaviors. Based on theory of planned behaviour Kaiser and Gutscher [3] reported low to medium strong correlations between environmental attitudes and environmental behaviour. There are many studies have attempted to trace the paths of influence between attitudes and behaviour has been guided by the theory of planned behavior [6]. This theory suggests that behavioural intention is the crucial antecedent to desired behavior and that attitudes affect behaviour to the extent that they influence intentions. It is argued that many of the factors that predict behaviour do so indirectly by first influencing intentions. For instance, study in customer decision making shows that objective environmental knowledge influence environmental attitude and further influence purchasing decision of green product [7].

Based on Ajzen's theory of planned behavior, Kaiser et.al [8] establishes environmental attitude as a powerful predictor of ecological behavior. Based on a structural equation model they confirmed the proposed model that environmental knowledge and environmental values explained 40 per cent of the variance of ecological behavior intension which in turn predicted 75 per cent of the variance of general ecological behavior. They concluded that three concepts, environmental knowledge, environmental values and ecological behavior intention are suggested as the conceptual skeleton of the theory of planned behavior. Moreover, these concepts are the core of most of the commonly used attitude approaches-attitudes toward the environment, the new environmental paradigm and attitudes toward ecological behavior-used to predict ecological behavior.

Several countries have been described by scholarly information about a nationwide scale concerning school or college students' knowledge, attitude and behavior towards environmental issues. In different contexts, several researches on the same theme have been done [9-12]. A survey conducted by Ivy et al [11] to gather baseline data on the level of environmental knowledge, attitudes and behavior of 1256 secondary three (Grade 9) and junior college year one (Grade 11) students in Singapore emphasized that majority of students gained most of their environmental knowledge from out-of-school sources rather than from general education at school. Meanwhile from Turkish context as mentioned by Cavas, Cavas, Tekkaya, Cakiroglu and Kesercioglu [13] it was found that 9th grade students have favorable attitudes toward environmental issues, eager to find solutions to environmental problems and show optimistic trends about the future. However, their interests in learning about environmental protection issues are in moderate level. In perspective of relationship between knowledge and behavior, study on secondary school students in Nigeria found that although students aware of environmental problems but they show poor practices to solve them [14].

At the university level Xueqin, H., et al. [15] examines environmental awareness among Chinese students (aged between 16 and 20 years) by considering the contrasting levels of regional economic development and environmental problems in the eastern/coastal and 
western/inland regions of China. The study found that students growing up in developed versus less-developed settings had significantly different levels of general environmental awareness despite their shared exposure to institutionalized environmental education.

Studies to investigate the level of awareness of environmental issues among students in higher education in Indonesia are still limited. For example Kusmawan et al. [16] investigated the interaction between teaching method and school locality in aligning student environmental beliefs, attitudes and intentions. Study involved 236 adolescent upper secondary school students and chemistry teachers in Indonesia who were completing environmental topics from the local science curriculum. The result mentioned that more active learning approaches seemed to promote cohesion between beliefs, attitudes and intentions, with participation in community issues having a greater impact on student ecological affinity than field research projects.

Meanwhile, environmental knowledge of university students have been investigated by involving 882 beginners and seniors of seven natural resourced related program in at the leading Indonesian institution of higher education in the field of natural resource management [17]. This finding concluded that many of the university students displayed substantial gaps in their capacity to solve complex, real-world natural resource management problems many of the university students displayed substantial gaps in their capacity to solve complex, realworld natural resource management problems especially the socio-economic and institutional knowledge domains. A message was conveyed to education planner to integrate with ecological knowledge with socio-economic and institutional knowledge.

One of important issue is often overlooked in studying ecological knowledge is the possible differing awareness among cultures can have on their natural environment. Some cultures might possess a traditional conservation ethic, coupled with a commitment to reduce or eliminate the problem [18]. Meanwhile, other cultures could have perceived little or no relationship between their activities and the state of their natural resources. In a study about indigenous community it was found that there is no statistically significant association between education and local environmental knowledge [19]. This means that the two forms of knowledge are complementary because they exist in parallel while the use of traditional pedagogical practices at school and the loss of traditional culture at home might obstruct local environmental learning. Meanwhile in national level, Trumper [20] suggests that it is important to develop environmental science education programs based on each country's own cultural, educational, and economic context. In his argument, this is compatible with a place-based pedagogy that promotes a narrative of local and regional politics adjusted to the particularities of where people actually live and linked to global development trends that impact local places.

\subsection{CONCEPTUAL FRAMEWORK}

Review of literatures above has mentioned that knowledge, attitude and behavior are suggested as interrelated construct that explain the phenomenon in human's response to environmental issue. In this context, theory of planned behavior may support the theoretical argument for this interrelationship. Despite its maturity, there is still area to explore interrelationship between knowledge, attitude and behavior of university students towards environmental issues in specific context like Indonesia. Review on previous studies have shown that to some extent localities differences should be considered as important factor in development of environmental sustainability education. A research context in a big country with multi ethnics and large area in an archipelago is expected to produce information that does not found elsewhere. Thus the following hypotheses are formulated:

H01: There is no statistically significant difference on environmental knowledge among student in three universities.

H02: There is no statistically significant difference on environmental attitude among students in three universities.

H03: There is no statistically significant difference on regulatory attitude among students in three universities.

H04: There is no statistically significant different on environmental behavior among students in three universities.

H61: Environmental knowledge significantly affect environmental behavior.

H62: Environmental knowledge significantly affect environmental attitude.

H63: Environmental knowledge significantly affect regulatory attitude.

H64: Environmental attitude significantly affect regulatory attitude.

H65: Environmental attitude significantly affect environmental behavior

H66: Regulatory attitude significantly affect environmental behavior.

\subsection{METHODOLOGY}

\section{Research Design}

As a relatively new issue within the context of Indonesia this research is exploratory in its nature. Based on the context of this study, it involved three universities as a research object. This is based on the consideration that by involving several objects it is expected that the results are more convincing and is considered more robust [21]. Therefore, the research conducted at Andalas University in West Sumatra, University of Indonesia in West Java and Udayana University in Bali. Selection of these three university carried out with consideration of variation of the background especially differences in local culture and main economic activities.

\section{Research Instrument and Participants}

This study use questionnaire to collect data from students of three universities as mentioned above. Questionnaire was designed based on previous study conducted by Kaiser et al. [8], Dunlap et al. [5] and Cordano, Welcomer, \& Scherer [22]. The combination of their study has been built into instrument for collecting data to capture quantitative data about knowledge, attitude and behavior. Measurement of each variable in the questionnaire was designed with close ended questions. Environmental knowledge is measured with two indicators. First, it measures student's knowledge about inter dependency among all living creatures including micro organism, plants animals and human being. Second measurement is student's knowledge that any the disappearance of animals in food chain could influence other animals. 
Environmental attitude is measured with eight indicators which represent regulatory and general environmental attitude. In general environmental attitude, students were asked for their response on six statements: (a) When humans interfere with nature it often produces disastrous consequences, (b) Humans are seriously abusing the environment, (c) The Earth has plenty of natural resources if we just learn how to develop them, (d) Plants and animals have as much right as humans to exist, (e) The balance of nature is very delicate and easily upset and (f) If things continue on their present course, we will soon experience a major ecological catastrophe. While for regulatory attitude students were asked for their response on two statements: (a) The higher level of environmental regulation enforcement and (b) There should be higher standards in environmental protection. Environmental behavior is measured with five indicators. (a) Participate in a protest to a company that endanger the environment, (b) Participate in protests against current environmental conditions, (c) Participate in green events, (d) Replace the current light bulbs with energy saving LED technology and (e) Use re-usable shopping bag.

The draft of questionnaires were pre-tested on selected group of respondent in order to minimize measurement error as suggested by Page \& Meyer [23]. Pre-test is a process to confirm the good aspect of the instrument and to reveal any weakness in wording or format and any omission. Pre-test in selected small number of target population asked for comments on the ease of understanding the questionnaire, ambiguity found and any other aspect of the instrument that could be improved.

Upon the completion of pre-test, pilot study was conducted by involving limited number of respondents within the sample frame. The pilot study was conducted to ensure the fulfillment of research quality standards. These standards were accomplished by having small-scale study to test the questions in the questionnaire, to minimize the likelihood of participants having problems in answering the questions and of data recording problems, to identify and then rectify any faulty and weakness in initial design of data collection protocol as well as to allow some assessment of the questions' validity and the reliability of the data that will be collected [24]. Data was analyzed with compare mean to confirm hypotheses on differences and relationship among knowledge, attitude and behavior of student in three universities. While partial least square modelling analysis used to confirm hypotheses on the relationship among knowledge, attitude and behaviour.

\subsection{RESULTS AND DISCUSSION}

\section{Compare Mean Analysis}

The questionnaire was distributed to 100 students in Andalas University, 89 students in University of Indonesia and 138 students in Udayana University. Compare mean analysis on environmental knowledge shows that there is significant difference among students in three universities on two measurements used. In the first measurement it was revealed that there is significant difference on student's knowledge about all living creatures including micro organism, plants animals and human being are dependent each others. In the second measurement it was also revealed that there is significant difference on student's knowledge that any the disappearance of animals in food chain could influence other animals. This result partly support previous studies by Xueqin, H., et al. [15] that found different environmental awareness based on geographical differences. The statistical results of compare mean test is shown in Table 1.

Table 1 ANOVA of compare means on environmental knowledge

\begin{tabular}{ccccccc}
\hline & Sum of Squares & df & Mean Square & F & Sig. & Results \\
\hline Indicator 1 & .478 & 3 & .159 & .337 & .798 & $\mathrm{H}_{0}$ rejected \\
\hline Indicator 2 & 1.606 & 3 & .535 & .749 & .523 & $\mathrm{H}_{0}$ rejected \\
\hline
\end{tabular}

Although the results of compare mean analysis show significant different in environmental knowledge indicators, however if it is seen from the raw data, all of answer are above 4. Score 4 represents good knowledge about the two indicators above. Student's response to two indicator in measuring environmental knowledge show that mean score of Andalas University students is relatively higher than others. The mean score of Andalas university students is 4.460 while Indonesia University is 4.398 and Udayana University is 4.380 .

On the second variable, environmental attitude was measured with six indicators as shown in Table 2 . The result of compare mean analysis shows that all six indicators were found significantly different among three sample groups.

Table 2 ANOVA of compare means on environmental attitude

\begin{tabular}{ccccccc}
\hline & Sum of Squares & Df & Mean Square & F & Sig. & Results \\
\hline Indicator 1 & 1.204 & 3 & .401 & .271 & .847 & $\mathrm{H}_{0}$ rejected \\
\hline Indicator 2 & 2.649 & 3 & .883 & .709 & .547 & $\mathrm{H}_{0}$ rejected \\
\hline Indicator 3 & 1.309 & 3 & .436 & .330 & .804 & $\mathrm{H}_{0}$ rejected \\
\hline Indicator 4 & .528 & 3 & .176 & .118 & .950 & $\mathrm{H}_{0}$ rejected \\
\hline Indicator 5 & .835 & 3 & .278 & .309 & .819 & $\mathrm{H}_{0}$ rejected \\
\hline Indicator 6 & 3.438 & 3 & 1.146 & 1.104 & .348 & $\mathrm{H}_{0}$ rejected \\
\hline
\end{tabular}

On this variable, the mean score of Udayana University students is the higher among others. The mean score is 3.934 while Andalas University is 3.878 and Indonesia University is 3.866. The range of mean scores above indicate fairly positive attitude towards environmental issues. This result slightly different with previous study for instance Aydin \& Çepni [25] where in case study of one university they found that students have positive attitudes towards environmental problems. 
On the regulatory attitude, measurement on two indicators shows that both of them are significantly different among three universities. First, students are significantly different in their attitude toward the higher level of environmental regulation enforcement. They are also significantly on attitude towards higher standards in environmental protection. This attitude is similar to previous finding that university students agree that the government should adopt and enforce formal environmental regulatory standards [26]. The result of compare mean analysis for both indicators shows those hypotheses are accepted. Table 3 shows that $p$-value of both indicators are greater than 0.05 . This means there significant difference on level of regulatory attitude among students in three universities. On regulatory attitude, students of Andalas University in relative show better attitude where the mean score of the response is 4.080. Meanwhile mean score of response of Udayana and Indonesia universities are 4.052 and 4.050 respectively.

Table 3 ANOVA of compare means on regulatory attitude

\begin{tabular}{lcccccc}
\hline & Sum of Squares & df & Mean Square & F & Sig. & Results \\
\hline Indicator 1 & 1.730 & 3 & .577 & .512 & .675 & $\mathrm{H}_{0}$ rejected \\
\hline Indicator 2 & 1.240 & 3 & .413 & .356 & .785 & $\mathrm{H}_{0}$ rejected \\
\hline
\end{tabular}

The last variable is environmental behavior with five measurement indicators. Compare mean analysis shows that all of them are significantly different as shown in Table 4.

Table 4 ANOVA compare means environmental behavior

\begin{tabular}{ccccccc}
\hline & Sum of Squares & df & Mean Square & $F$ & Sig. & Results \\
\hline Indicator 1 & 3.756 & 3 & 1.252 & .990 & .397 & $\mathrm{H}_{0}$ rejected \\
\hline Indicator 2 & 3.796 & 3 & 1.265 & 1.220 & .302 & $\mathrm{H}_{0}$ rejected \\
\hline Indicator 3 & .462 & 3 & .154 & .146 & .932 & $\mathrm{H}_{0}$ rejected \\
\hline Indicator 4 & .825 & 3 & .275 & .248 & .862 & $\mathrm{H}_{0}$ rejected \\
\hline Indicator 5 & 1.784 & 3 & .595 & .463 & .709 & $\mathrm{H}_{0}$ rejected \\
\hline
\end{tabular}

On environmental behavior, students of Andalas university show mean score of response 3.682 which is higher than other universities. Mean score of Udayana university students is 3.671 and Indonesia university student is 3.588 . This range of mean score indicates that university students in general are fairly interested to participate on five environmental friendly actions.

Based on comparison of mean score for each indicator in three variables, there is variation on the position of each university. Mean score of Andalas university students is relatively higher than other two universities in environmental knowledge, regulatory attitude and environmental behavioral. Meanwhile, mean score of Udayana universities is relatively higher than others in environmental attitude. One of plausible support for this finding is possible association between local knowledge and academic knowledge where contextualized learning might help avoid that the provision of universal education comes at the cost of humanity's cultural diversity [27].

Model Testing: reliability and validity of the measurement model

As mentioned by Fornell and Larker [28], reliability means the internal consistency index. The traditional criterion for internal consistency is Cronbach's alpha which provides an estimate for the reliability based on the indicator inter-correlations. However, as mentioned by Henseler, Ringle and Sinkovics [29], Cronbach's alpha tends to provide a severe underestimation of the internal consistency reliability of latent variables in PLS path models, thus it is more appropriate to apply the composite reliability. The composite reliability takes into account that indicators have different loadings and can be interpreted in the same way as Cronbach's alpha. No matter which particular reliability coefficient is used, an internal consistency reliability value above 0.7 in early stages of research and values above 0.8 or 0.9 in more advanced stages of research are regarded as satisfactory, whereas a value 0.6 indicates a lack of reliability. The reliability of the measures for seven latent variables in this study is reported satisfactory as shown by the composite reliability in Table 5 .

Table 5 Overview of model quality criteria

\begin{tabular}{ccccccc}
\hline LV & AVE & Composite Reliability & R Square & Cronbachs Alpha & Communality & Redundancy \\
\hline EA & 0.629 & 0.910 & 0.045 & 0.882 & 0.629 & 0.028 \\
\hline EB & 0.593 & 0.879 & 0.323 & 0.829 & 0.593 & 0.020 \\
\hline EK & 0.741 & 0.851 & 0.000 & 0.668 & 0.741 & 0.000 \\
\hline RA & 0.832 & 0.908 & 0.552 & 0.798 & 0.832 & 0.459 \\
\hline
\end{tabular}

Note: EA=Environmental Atttitude, EB=Environmental Behavior, EK=Environmental Knowledge, RA=Regulatory Attitude 
There two validity sub types are usually examined [29]: the convergent validity and the discriminant validity. Convergent validity indicates that a set of indicators represents one and the same underlying construct, which can be demonstrated through their uni-dimensionality. Fornell and Larcker [28] suggest using the average variance extracted (AVE) as a criterion of convergent validity. An AVE value of at least 0.5 or higher are said to exhibit convergent validity or indicates sufficient convergent validity, meaning that a latent variable is able to explain more than half of the variance of its indicators on average [30]. The AVEs reported in Table 5 above shows that all of variables exceed 0.50 , confirming that measures demonstrate satisfactory convergent validity.

Discriminant validity is a rather complementary concept: Two conceptually different concepts should exhibit sufficient difference (i.e. the joint set of indicators is expected not to be uni-dimensional). In PLS path modelling, two measures of discriminant validity have been put forward: The Fornell-Larcker criterion and the cross-loadings [29]. The Fornell-Larcker criterion postulates that a latent variable shares more variance with its assigned indicators than with any other latent variable. The second criterion of discriminant validity is usually a bit more liberal: The loading of each indicator is expected to be greater than all of its cross-loadings [30].

Discriminant validity is established from the latent variable correlation matrix. This matrix has the square root of AVE for the measures on the diagonal and the correlations among the measures as the off-diagonal elements. The matrix has to be constructed from the PLS output. Discriminant validity is determined by looking down the columns and across the rows. When the diagonal elements are greater than all off-diagonal elements, discriminant validity is satisfactory. Table 6 shows that discriminant validity of latent variables is satisfactory.

Table 6 Discriminant validity of variable constructs

\begin{tabular}{lcccc}
\hline & EA & EB & EK & RA \\
\hline Environmental Attitude & $\mathbf{0 . 7 9 3}$ & & & \\
\hline Environmental Behavior & 0.582 & $\mathbf{0 . 7 7 0}$ & & \\
\hline Environmental Knowledge & 0.212 & 0.215 & $\mathbf{0 . 8 6 1}$ & \\
\hline Regulatory Attitude & 0.743 & 0.559 & 0.205 & $\mathbf{0 . 9 1 2}$ \\
\hline
\end{tabular}

\section{Structural Model: Path Coefficients And Predictive Ability}

The structural model in Figure 1 presents information about the coefficient of determination the path significance $\left(\mathrm{R}^{2}\right)$ and the path coefficients $(\beta)$ of hypothesised relationships. The $\mathrm{R}^{2}$ or the coefficient of determination provides indication of the predictive ability of the independent variables (Henseler et al., 2009). As suggested by Chin (1998) $\mathrm{R}^{2}$ values of 0.67, .33, and 0.19 in PLS path models as substantial, moderate, and weak, respectively. The coefficient of determination for four endogenous variables is 0.0455 for Environmental Attitudes (EA), 0.323 for Environmental Behavior (EB) and 0.552 for Regulatory Attitude (RA).

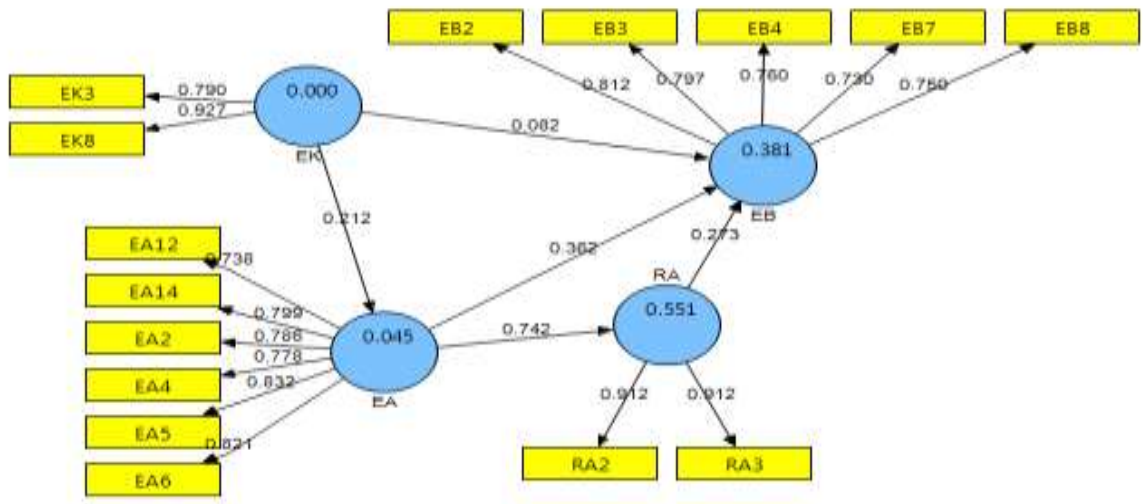

Figure 1 The path coefficients $(\beta)$ and the $\mathrm{R}^{2}$

According to Henseler et al., [29], if a certain inner path model structures explain an endogenous latent variable by only a few (e.g., one or two) exogenous latent variables, "moderate" $\mathrm{R}^{2}$ may be acceptable. However, if the endogenous latent variable relies on several exogenous latent variables, the $\mathrm{R}^{2}$ value should exhibit at least a substantial level. This study indicates that strategic response has weak $\mathrm{R}^{2}$ where the independent variable has low predictive ability. Stakeholder salience and environmental strategy adaptation is considered to provide adequate evidence of the predictive ability of the model.

Tenenhaus, Vinzi, Chatelin and Lauro [31] note that tests for predictive relevance of a model can be gauged from its Goodness-of-Fit index $(\mathrm{GoF})$ and Stone-Geiser q-square $\left(\mathrm{Q}^{2}\right)$ indicators. The Goodness-of-Fit $(\mathrm{GoF})$, which is the geometric mean of the average communality (outer measurement model) and the average $\mathrm{R}^{2}$ of endogenous latent variables, is used to assess the overall fit of the model. It is defined as follows:

$$
G o F=\sqrt{\left(\overline{\text { Communality }} * \overline{R^{2}}\right)}
$$


The GoF validates the PLS model by presenting a compromise between the performance of the measurement and the structural model; it is normalised between 0 and 1 where a high value indicates better path model estimation. The calculation of GoF of the structural model found the value of 0.399 which is considered as low to medium strong.

The $\mathrm{Q}^{2}$ statistic measures the predictive relevance of the model. The model's predictive validity can be tested by means of the nonparametric Stone-Geisser test. Similar to the determination coefficient $\left(\mathrm{R}^{2}\right)$ in OLS, the Stone-Geisser test criterion $\mathrm{Q}^{2}$ is interpreted without loss of degrees of freedom. It shows how well the data collected empirically can be reconstructed with the help of the model and the PLS parameters [32].

Value of $\mathrm{Q}^{2}$ is ranged $0<\mathrm{Q}^{2}<1$, where close to 1 indicate a good model. When the value of $\mathrm{Q}^{2}$ greater than 0 means that the model has predictive relevance and values close to 0 indicate a lack of predictive relevance. The $\mathrm{Q}^{2}$ calculation in this model produces value 0 f $\mathrm{Q}^{2}$ as follow: 0.045 for EA, 0.552 for RA and 0.323 for EB. This result indicates various predictive relevance is demonstrated for three endogenous constructs.

The path coefficients, or the inner model, show the significance level of hypotheses tests. As suggested by Hair, Sarstedt, Ringle and Mena [33] the T-statistics of the inner model must be greater than 1.96 for two-tailed hypotheses and greater than 1.64 for one-tailed hypotheses with the significance level of 5\%. The test of structural model is displayed on Table 7.

Table 7 Path Coefficient (Mean, STDEV, T-Values)

\begin{tabular}{cccccc}
\hline & $\begin{array}{c}\text { Original } \\
\text { Sample (O) }\end{array}$ & $\begin{array}{c}\text { Sample Mean } \\
(\mathrm{M})\end{array}$ & $\begin{array}{c}\text { Standard Deviation } \\
(\text { STDEV })\end{array}$ & $\begin{array}{c}\text { Standard Error } \\
(\text { STERR })\end{array}$ & $\begin{array}{c}\text { T Statistics } \\
(|\mathrm{O} / \mathrm{STERR}|)\end{array}$ \\
\hline EA -> EB & 0.400 & 0.394 & 0.104 & 0.104 & 3.828 \\
\hline EA -> RA & 0.743 & 0.736 & 0.071 & 0.071 & 10.534 \\
\hline EK -> EA & 0.212 & 0.233 & 0.101 & 0.101 & 2.109 \\
\hline EK -> EB & 0.190 & 0.215 & 0.105 & 0.105 & 1.812 \\
\hline EK -> RA & 0.157 & 0.172 & 0.077 & 0.077 & 2.037 \\
\hline RA -> EB & 0.538 & 0.530 & 0.114 & 0.114 & 4.739 \\
\hline
\end{tabular}

Table 7, presents the path coefficient and t-statistic to show the significance effect of exogenous variables on environmental behavior. The data did not support H61 where environmental knowledge does not affect environmental behavior intention $(\beta=0.001$, $\mathrm{t}$-value $=$ 1.812). The obtained result is not statistically significant at 0.95 confident intervals and hypothesis was not supported. It is somewhat not surprising that hypotheses $\mathrm{H}_{2}$ environmental knowledge is significantly affect environmental attitude where the $\beta$ is 0.212 and a $\mathrm{t}-\mathrm{value}$ is 2.109. Hypotheses $\mathrm{H}_{3}$ was supported to indicate that environmental knowledge have significant effect on regulatory attitude where the $\beta$ is 0.157 and a t-value is 2.037 . For $\mathrm{H}_{4}$ environmental attitude further has significant effect on regulatory attitude the $\beta$ is 0.743 and a $\mathrm{t}$ value is 10.534 . For $\mathrm{H}_{5}$ environmental attitude was found significantly affect environmental behavior intention where the $\beta$ is 0.400 and a $\mathrm{t}$-value is 3.828 . Meanwhile, for $\mathrm{H}_{6} 6$ regulatory attitude was also found significantly affect environmental behavior intention with the $\beta$ is 0.538 and a t-value is 4.739 .

\subsection{CONCLUSION}

In relation to the context of current study at higher education institution, education and training are argued as very important factor to develop appropriate knowledge, positive attitude and pro environmental behavior [34]. Individuals that make up society should be provided access to accurate information and education should be given according to this figure. Environmental education should be given shape to provide people to accept responsibility to preserve the environment by bringing people environment-related knowledge, awareness, skills and values. Environmental education is not just an element of the learning process, an element of an individual's entire life cycle. Therefore, environmental education should be addressed and considered in the model of lifelong learning. In universities educational activities can be carried out by supporting the work of universities for the club and associations. Student participation should be provided to the scientific researches such as conference about the environment, panel discussions and seminars. As suggested by RuizMallen, Barraza, Bodenhorn and Reyes-Garcia [35] the inclusion of participatory environmental education programmes would improve the acquisition of ecological knowledge.

The survey has confirmed and supports five out of six predictive relationships among environmental knowledge, attitude and behavior. It demonstrated the relationship that has been mentioned in the theory of planned behavior. This exploratory research was employed based on the rationale that it will provide contextual understanding on broad relationship among variables and help to develop instrument for further studies. This study has revealed that only $32.3 \%$ of environmental behavior intention was affected by environmental knowledge and attitude. This should be seen as a room for further investigation where behavior related to environment is much more influenced by other factors.

Upon the accomplishment of this study, some rooms for further research were identified. Study about university environmentalism should comprehensively involve all elements from high rank management, employees, students, lecturer and relevant stakeholders. The current study has presented perspective from students in three different universities in Indonesia where in fact population of universities much larger. Thus, further investigation should involve bigger number of university stakeholders. In addition, further research may involve bigger population of university. Multi sources of evidences and multi perspective should produce result that is considered as robust. Last but not least, further research may analyze the causal relationship among variables. The results of this research theme may contribute to university policies and efforts in maintaining their role as change agent through teaching, research and community development 


\section{Acknowledgements}

This research is funded by Andalas University through Hibah Bersaing research grant based on contract number: Dipa023.04.2.415061/2014, December 52013.

\section{References}

Ajzen, I. (1991). The theory of planned behavior. Organizational Behavior and Human Decision Processes, 50(2), 179-211.

Alkan, H. \& Ogurlu, I. (2014). The changes in the environmental perception, attitude and behaviour of participants at the end of nature training projects. Environmental Engineering and Management Journal, 13(2), 419-428.

Alp, E., et al. (2000). A statistical analysis of children's environmental knowledge and attitudes in Turkey. International Research in Geographical and Environmental Education, 15(3), 210-223

Aydin, F. \& Çepni, O. (2010). University students' attitudes towards environmental problems: A case study from Turkey. International Journal of Physical Sciences, $5(17), 2715-2720$.

Barber, N., Taylor, D.C., \& Strick, S. (2009). Environmental knowledge and attitudes: influencing the purchase decisions of wine consumers. International CHRIE Conference. University of Massachusetts - Amherst.

Cavas, B., et al. (2009). Turkish Students' Views on Environmental Challenges with respect to Gender: An Analysis of ROSE Data. Science Education International, 20, 69-78.

Chin, W.W. (1998). Commentary: Issues and opinion on structural equation modeling. MIS Quarterly, 22(1), vii-xvi.

Cordano, M., Welcomer, S.A., \& Scherer, R.F. (2003). An analysis of the predictive validity of the new ecological paradigm scale. The Journal of Environmental Education, 34(3), 22-28.

Duerden, M.D. \& Witt, P.A. (2010). The impact of direct and indirect experiences on the development of environmental knowledge, attitudes, and behavior. Journal of Environmental Psychology, 30(4), 379-392.

Dunlap, R.E., et al. (2000). New trends in measuring environmental attitudes: measuring endorsement of the new ecological paradigm: a revised NEP scale. Journal of Social Issues, 56(3), 425-442.

Fornell, C. \& Cha, J. (1994). Partial least squares. In Bagozzi, R. P. (Ed.) Advanced Methods of Marketing Research. Cambridge, MA: Blackwell, 52-78.

Fornell, C. \& Larcker, D.F. (1981). Evaluating structural equation models with unobservable variables and measurement error. Journal of Marketing Research, 18(1), $39-50$.

Fukukawa, K., Shafer, W., \& Lee, G. (2007). Values and attitudes toward social and environmental accountability: A study of MBA students. Journal of Business Ethics, 71(4), 381-394

Hair, J.F., et al. (2012). An assessment of the use of partial least squares structural equation modeling in marketing research. Journal of the Academy of Marketing Science, 40(3), 414-433.

Henseler, J.R., Ringle, C. \& Sinkovics, R. (2009). The use of partial least squares path modeling in international marketing. Advances in International Marketing (AIM), 20, 277-320.

Hvenegaard, G. (2007). A Novel Approach to Deepen Understanding of Undergraduates' Environmental Backgrounds. International Research in Geographical \& Environmental Education, 16(4), 328-338

Ifegbesan, A. (2010). Exploring Secondary School Students' Understanding and Practices of Waste Management in Ogun State, Nigeria. International Journal of Environmental and Science Education, 5(2), 201-215.

Ivy, T.G.C., et al. (1998). A survey of environmental knowledge, attitudes and behaviour of students in Singapore. International Research in Geographical and Environmental Education, 7(3), 181-202.

Johannes, R.E. (1993). Integrating traditional ecological knowledge and management with environmental impact assessment. In Inglis, J.T. (Ed.) Traditional Ecological Knowledge: Concepts and Cases. Ottawa: International Development Research Centre, 33-39.

Kaiser, F.G. \& Gutscher, H. (2003). The proposition of a general version of the theory of planned behavior: predicting ecological behavior. Journal of Applied Social Psychology, 33(3), 586-603.

Kaiser, F.G., Wolfing, S., \& Fuhrer, U. (1999). Environmental attitude and ecological behaviour. Journal of Environmental Psychology, 19(1), 1-19.

Koch, S., et al. (2013). Knowledge of Indonesian university students on the sustainable management of natural resources. Sustainability, 5(4), 1443-1460.

Kusmawan, U., et al. (2009). Beliefs, attitudes, intentions and locality: the impact of different teaching approaches on the ecological affinity of Indonesian secondary school students. International Research in Geographical and Environmental Education, 18(3), 157-169.

Page, C. \& Meyer, D. (2000). Applied Research Design for Business and Management. Sydney: McGraw-Hill.

PDD Dikti (2014). Grafik Jumlah Perguruan Tinggi. Pangkalan Data Pendidikan Tinggi. Retrieved on December 10, 2014. http://forlap.dikti.go.id/perguruantinggi/homegraphpt.

Reyes-Garcia, V., et al. (2010). Schooling and local environmental knowledge: Do they complement or substitute each other? International Journal of Educational Development, 30(3), 305-313.

Ruiz-Mallen, I., et al. (2009). Evaluating the impact of an environmental education programme: an empirical study in Mexico. Environmental Education Research, $15(3), 371-387$

Ruiz-Mallen, I., et al. (2009). School and local environmental knowledge, what are the links? A case study among indigenous adolescents in Oaxaca, Mexico. International Research in Geographical and Environmental Education, 18(2), 82-96.

Saunders, M., Lewis, P. \& Thornhill, A. (2009). Research Methods for Business Students. 5th ed. Milan: Pearson Education.

Tenenhaus, M., et al. (2005). PLS path modeling. Computational Statistics \& Data Analysis, 48(1), 159-205.

Trumper, R. (2010). How Do Learners in Developed and Developing Countries Relate to Environmental Issues? Science Education International, 21(4), 217-240.

Tuncer, G. (2008). University students' perception on sustainable development: a case study from Turkey. International Research in Geographical and Environmental Education, 17(3), 212-226.

Wright, T.A. (2002). Definitions and frameworks for environmental sustainability in higher education. International Journal of Sustainability in Higher Education, $3(3), 203-220$

Xueqin, H., et al. (2011). A comparative study of environmental knowledge, attitudes and behaviors among university students in China. International Research in Geographical and Environmental Education, 20(2), 91-104.

Yin, R.K. (2003). Case study research: Design and methods. Applied Social Research Methods Series, 5. California: Sage Publications 